\title{
Heat Transfer Characteristics of R-134a in a Converging-Diverging Nozzle
}

\author{
G.W. Mann ${ }^{\mathrm{a}, *}$, G.R. Madamadakala ${ }^{\mathrm{a}}$, S.J. Eckels ${ }^{\mathrm{a}}$ \\ ${ }^{a}$ Institute for Environmental Research, 64 Seaton Hall, Manhattan, KS 66506
}

\begin{abstract}
Heat transfer characteristics of cavitating flows in the diverging section of a converging-diverging nozzle, with R-134a as the working fluid were investigated for mass fluxes from $11.3-52.3 \mathrm{~kg} \mathrm{~m}^{-2} \mathrm{~s}^{-1}$ and heat fluxes from $52.6-693 \mathrm{~kW} \mathrm{~m}^{-2}$. Eleven different nozzle configurations were examined with different divergence angles, throat diameters, inlet profiles, and lengths. Heat flux measurement assumptions were analyzed using numerical conduction simulations with ANSYS Fluent. Experimental results indicated two different heat transfer regimes at high Reynolds number - one high and one low-likely due to wall dryout. A temperature drop with a strong correlation to Reynolds number as well as inlet profile was recorded due to the cavitationinduced phase change. Additionally, data showed two-phase heat transfer coefficients from 3.7 to as high as $285 \mathrm{~kW} \mathrm{~m}^{-2} \mathrm{~K}^{-1}$. Chen's correlation compared well with the recorded heat transfer coefficients for low Reynolds numbers. Variation of heat transfer coefficients with different geometry parameters were given, and potential sonic effects were discussed. With such high heat transfer coefficients, cavitation enhanced heat transfer in converging-diverging nozzles could be of significant use in electronics cooling applications. Keywords: two-phase flow, critical flow, heat transfer enhancement, cavitation, sonic flow, converging-diverging nozzle
\end{abstract}

\section{Introduction}

Cavitating flows, even through simple geometries, have complex flow dynamics and mechanisms that are difficult to analyze. In order to set the context for a discussion of these flows, we present a one dimensional, frictionless liquid flowing through the converging-diverging nozzle of Figure 1. Below the nozzle are a set of pressure vs. distance curves illustrating the behavior of the fluid at successively lower back-pressures. The fixed inlet pressure $\left(P_{0}\right)$ of the fluid is set above its initial saturation pressure.

Initially, with a back-pressure slightly below the inlet pressure (1), pressure drops at the throat due to the increase of velocity enforced by the continuity equation, but there is not phase change. Post-throat, pressure increases as cross-sectional area diverges. At some lower back-pressure (2), the low pressure region

\footnotetext{
* Corresponding author

Email addresses: gmann@ksu.edu (G.W. Mann), ganeshreddy.647@gmail.com (G.R. Madamadakala), eckels@ksu.edu (S.J. Eckels)
} 


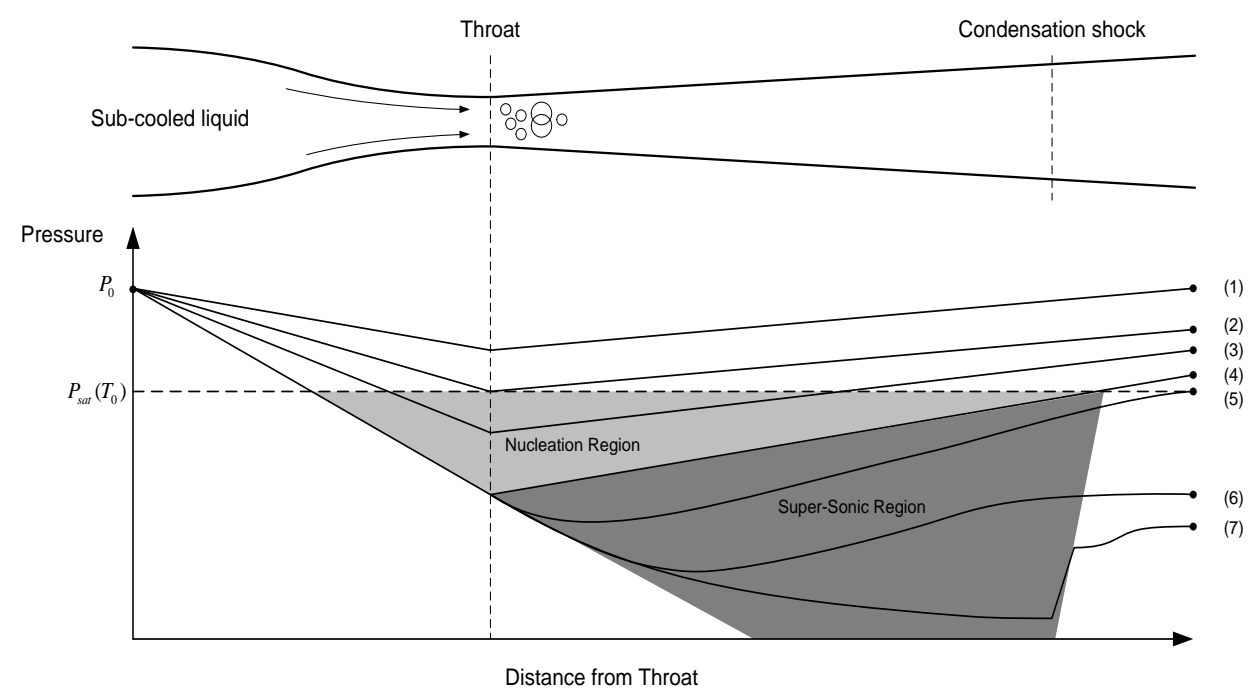

Figure 1: Pressure lines for ideal flow through a converging-diverging nozzle.

at the throat reaches the saturation point. Typically, this does not cause nucleation, as some superheat of the liquid is required to enact bubble formation [1].

Further reduction in the back-pressure causes the liquid to enter a metastable state. This is denoted on Figure 1 as the nucleation region. It is theoretically possible for nucleation to occur anywhere in this zone, either before or after the throat. Once nucleation occurs, bubbles will grow in finite time towards equilibrium. Though in some cases, equilibrium can be reached immediately via an expansion wave where the fluid properties discontinuously change across the wave front [1-3]. Depending on the size of the bubbles, degree of superheat, velocity, and length of the nozzle, the fluid may or may not reach equilibrium by the exit.

Due to the fact that the speed of sound in a two phase mixture is significantly lower than speed of sound in either a saturated liquid or a saturated vapor, when nucleation actually occurs, the flow may immediately become supersonic. In the case of only sub-sonic flow upon nucleation, further acceleration of the flow or decrease of the sonic velocity may occur leading to the sonic condition (4). Any further reduction in the back-pressure after the sonic condition is reached does not increase the flow rate through the nozzle, i.e. the nozzle is choked. Additionally, after the sonic condition is reached, the pressure may continue to decrease in the diverging section of the nozzle, and the flow accelerate. While for single phase fluid, the local Mach number must be unity at the throat of the nozzle (in the inviscid case), in a two-phase fluid, because of metastable conditions and bubble dynamics, this may not occur (e.g. [1, 4]).

The accelerating region of the fluid will continue along the diverging section. However, since the flow must meet the back-pressure condition, in the ideal case, a condensation shock, where the pressure discontinuously 
increases, will occur (7), as has been observed in $[5,6]$. In non-ideal flow where viscous effects and acoustic dissipation can increase the pressure of the flow, the flow may not form a distinct condensation shock, but through a series of mini-shocks will transition slowly back to the back-pressure condition (6).

Various models have been proposed to predict the characteristics of cavitating flows. The classical method is to solve the 1D conservation equations for a homogeneous mixture. Doing this with an appropriate barotropic equation allows for critical flow rates and choked pressure ratios to be determined (see $[7,8]$ and review by [9]). Extensions of this approach accounting for slip [10] or transport equations for void fraction [11] have been proposed. More complicated models solve the Rayleigh-Plesset bubble equation dynamically to address non-equilibrium effects [12-16].

For fluids that are used at working conditions sufficiently close to the critical point, generation of vapor bubbles causes local temperature of the fluid to decrease significantly. This has primarily been studied because of the way local temperature decrease at the vapor/liquid interface changes fluid properties and slows the growth rate of bubbles $[11,15,17,18]$. Very little work has been done exploring the affect local temperature drop has on heat transfer between the fluid and the wall. It is hypothesized that the temperature depression of the fluid combined with vigorous phase change along the nozzle stimulates high heat transfer coefficients. Understanding the relationship between the thermodynamic state of the fluid, geometry of the nozzle, and amount of heat transfer is important in various applications of this phenomena. For example, enhancing heat transfer in two-phase electronics cooling applications is continually important as chip power density increases. Additionally, evidence suggests that for some materials, cavitation damage is proportional to material temperature [19]; thus, predicting erosion rates and seal failure in control valves or pressure relief valves during cavitation may be improved by a knowledge of heat transfer between the flow and solid surfaces.

Recent work in this area has been performed for two-phase flow in microchannels. Schneider et al. [20] consider cavitating flow through an orifice in a microchannel and measure heat transfer coefficients for different cavitating numbers. They show a $67 \%$ improvement in heat transfer over the non-cavitating case with heat transfer coefficients as high as $50 \mathrm{~kW} \mathrm{~m}^{-2} \mathrm{~K}^{-1}$. Cole et al. [21] explore whether this phenomena might be useful in a thermal management system. Sole et al. [22] study a similar application of cavitation to microchannel heat transfer enhancement for R-134a, showing heat transfer coefficients as high as $100 \mathrm{~kW}$ $\mathrm{m}^{-2} \mathrm{~K}^{-1}$ for mass fluxes in the range of 500-1000 $\mathrm{kg} \mathrm{m}^{-2} \mathrm{~s}^{-1}$. Yuan et al. [23] also study this enhancement, documenting an increase in heat transfer with an increase of heat flux and a decrease in quality. All of these studies focused on microchannel orifices.

More classic flow boiling has been experimentally studied in a broad range of geometries, conditions, and fluids. Examples of recent experimental heat transfer work with R-134a are Romstedt and Werner [24] with mass fluxes from $50-200 \mathrm{~kg} \mathrm{~m}^{-2} \mathrm{~s}^{-1}$ and measured heat transfer coefficients from $5000-30,000 \mathrm{~W} \mathrm{~m}{ }^{-2}$ $\mathrm{K}^{-1}$; Kanizawa et al [25] with mass fluxes from $75-200 \mathrm{~kg} \mathrm{~m}^{-2} \mathrm{~s}^{-1}$ and measured heat transfer coefficients 
from 1500-4000W m $\mathrm{W}^{-2} \mathrm{~K}^{-1}$; and do Nascimento et al. [26] with mass fluxes from 400-1500 $\mathrm{kg} \mathrm{m}^{-2} \mathrm{~s}^{-1}$ and heat transfer coefficients as high as $36 \mathrm{~kW} \mathrm{~m}^{-2} \mathrm{~K}^{-1}$. Most work has been done with lower mass fluxes than considered in this paper. One paper experimentally studying critical heat flux did study cases with mass fluxes in this range - up to $38,000 \mathrm{~kg} \mathrm{~m}^{-2} \mathrm{~s}^{-1}$ [27]. Only critical heat flux was reported; no heat transfer coefficients were given.

In this paper, heat transfer characteristics of cavitating two-phase flow through a converging-diverging nozzle are studied. A thermo-sensitive fluid-R-134a - is used. How different geometries and flow conditions affect temperature drop and local heat transfer coefficients is described. The remainder of the paper is organized as follows: Section 2 gives a description of the experimental setup, test conditions, data reduction, and uncertainty analysis, and in Section 3, results are presented and discussed.

\section{Experimental Description}

\subsection{Test Section Geometry}

The nozzles used in this study were composed of multiple, cylindrical elements - or pucks-fastened together and sealed with O-rings (see Figure 2a). This approach was prompted by manufacturing limitations. For all nozzle configurations, the converging portion was machined from a single puck of aluminum. The diverging portion was composed of ten to eighteen pucks ranging from 10 to $23 \mathrm{~mm}$ in length. Great care was taken in the design to center and match section dimensions. Each of the nozzle pucks had fixtures for a temperature sensor and pressure transducer. Temperature sensor taps were drilled to within $1 \mathrm{~mm}$ of the internal passage. Pressure tap diameters were small $(<0.5 \mathrm{~mm})$, allowing the pressure transducers to measure accurate static pressure. Each nozzle assembly also had two holes for mounting $6.29 \mathrm{~mm}$ diameter cartridge heaters in the outer portion of the aluminum section away from the passage. The outer surface of the nozzle assembly was well insulated during the experiments with foam insulation. Data from eleven different nozzle assemblies were collected in this study. Table 1 shows relevant dimensions of each. These configurations represent four different throat diameters, three heater lengths, two inlet angles, and six nozzle inlet profiles. Outer diameter of all of pucks was $54 \mathrm{~mm}$.

Figure $2 \mathrm{~b}$ compares the converging inlet profiles for the six different inlet types. Inlet $\mathrm{A}$ has an exponential curve with filleted corners. Inlets $\mathrm{C}$ and D are formed from tangent-matched radii. B1 and B2 are square inlets with no transition profile, and $\mathrm{E}$ is a square profile with a filleted edge. The upstream diameter was the same for all profiles.

\subsection{Experimental Apparatus}

Several flow circuits were integrated to provide high pressure refrigerant at the appropriate inlet temperature to the test section. Figure 3 shows the schematic diagram of the experimental facility consisting of the 


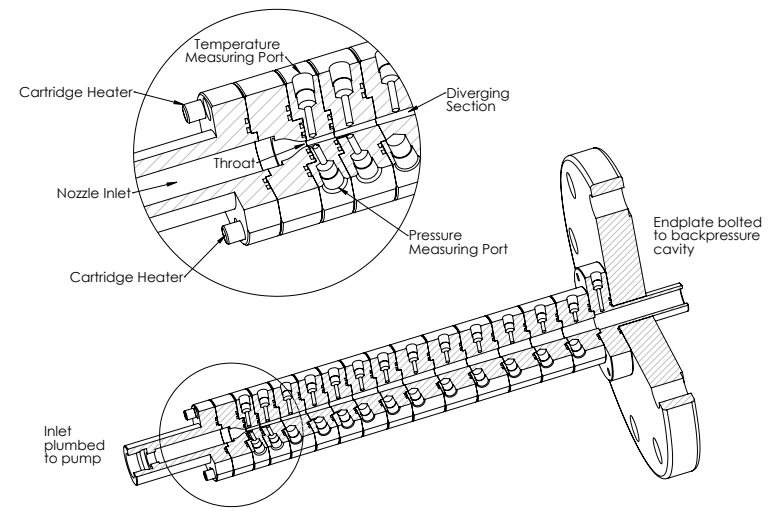

(a) Schematic of nozzle assembly

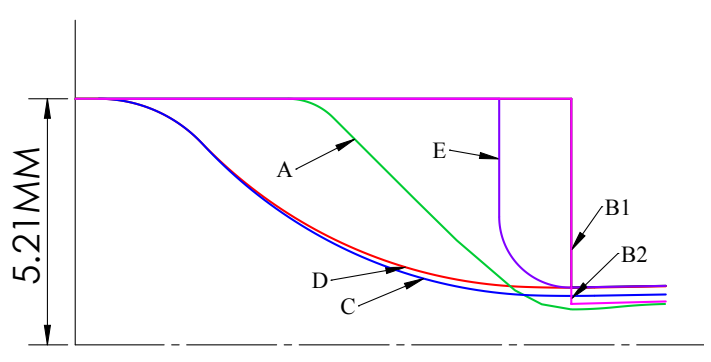

(b) Nozzle inlet profiles

Figure 2: Description of nozzle assembly.

\begin{tabular}{c|ccccccccccc}
\hline \hline & \multicolumn{1}{|c}{ Nozzle Assembly } \\
& 1 & 2 & 3 & 4 & 5 & 6 & 7 & 8 & 9 & 10 & 11 \\
\hline Throat diameter $(\mathrm{mm})$ & 1.5 & 1.5 & 1.73 & 2.08 & 2.08 & 2.43 & 2.43 & 2.43 & 2.43 & 2.43 & 2.43 \\
Length of nozzle (mm) & 9.59 & 11.08 & 9.59 & 11.08 & 14.6 & 11.08 & 14.6 & 11.09 & 14.6 & 11.09 & 14.6 \\
Length of nozzle (mm) & 227.7 & 347 & 150 & 332.4 & 433 & 264.4 & 422.8 & 248.7 & 412.3 & 248.7 & 412.3 \\
Diverging angle & $1.5^{\circ}$ & $1^{\circ}$ & $1.5^{\circ}$ & $1^{\circ}$ & $1^{\circ}$ & $1^{\circ}$ & $1^{\circ}$ & $1^{\circ}$ & $1^{\circ}$ & $1^{\circ}$ & $1^{\circ}$ \\
Heater length (mm) & 127 & 203.2 & 127 & 203.2 & 254 & 203.2 & 254 & 203.2 & 203.2 & 203.2 & 254 \\
Throat type & $\mathrm{A}$ & $\mathrm{A}$ & $\mathrm{B} 1$ & $\mathrm{C}$ & $\mathrm{C}$ & $\mathrm{D}$ & $\mathrm{D}$ & $\mathrm{E}$ & $\mathrm{E}$ & $\mathrm{B} 2$ & $\mathrm{~B} 2$ \\
\hline
\end{tabular}

Table 1: Nozzle assembly dimensions. 
nozzle test section, refrigerant loop, back-pressure loop, and two water loops. The temperature of the inlet to the test section was controlled using the water loops. The back-pressure on the nozzle was set through the temperature of the back-pressure control tank - containing a two-phase mixture of refrigerant liquid and vapor. The back-pressure control tank was at the highest point of the system keeping a positive suction pressure on the pump. Temperatures of the water loops were maintained by switched electric immersion heaters and heat exchangers connected to domestic cooling water.

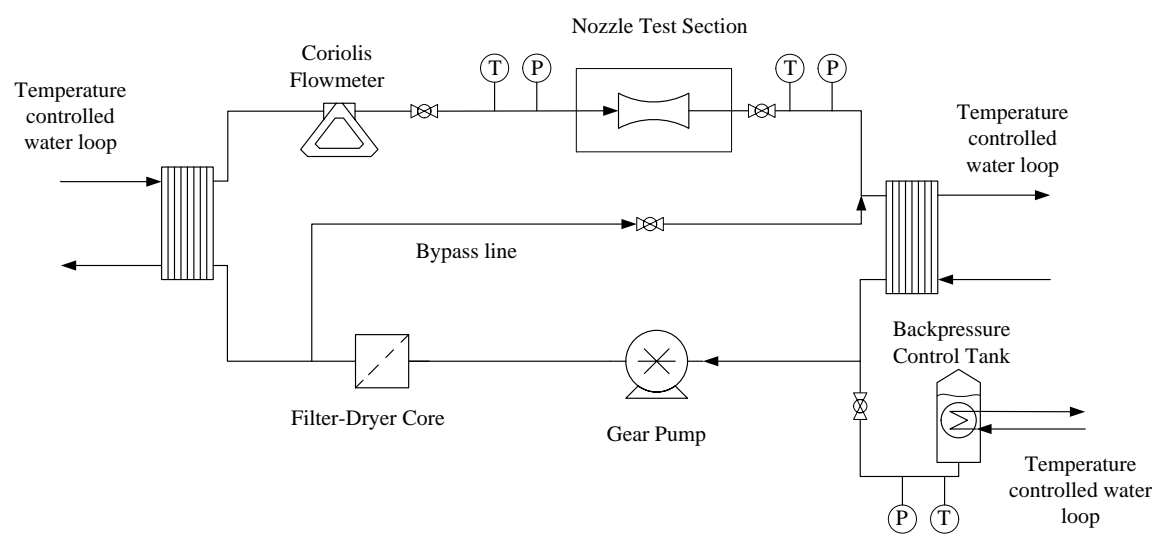

Figure 3: Schematic of experimental facility

Besides the temperature and pressure measurements on each puck in the test section, temperature and pressure was measured at the inlet and outlet of the test section and at the back-pressure control tank. All fluid temperatures were measured using type-K thermocouples calibrated to lab standard thermometers within $\pm 0.15{ }^{\circ} \mathrm{C}$. Pressure transducers used were strain-gage, absolute type with an uncertainty of $\pm 0.05 \%$ of full scale and were calibrated with a lab deadweight tester. Range of all pressure transducers was 0$1000 \mathrm{kPa}$, except the inlet pressure transducer, which had a range of 0-3500 kPa. The flow meter used was Coriolis-effect type with an uncertainty of $\pm 0.1 \%$ of reading. Heater power was measured via the AC voltage across the heaters with the heater resistance. All sensors were measured and recorded using an Agilent 34970A data acquisition unit.

\subsection{Experimental Procedure}

Data were collected from each of the different nozzle configurations at different throat velocities and saturation pressures. Table 2 shows the operating conditions the tests.

Refrigerant for all runs was R-134a. Table 3 gives properties of R-134a at saturation conditions for both inlet temperatures, where

$$
\Delta T^{*}=\frac{\rho_{g} i_{f g}}{\rho_{f} C_{p, f}}
$$




\begin{tabular}{lllll}
\hline $\begin{array}{l}\text { Nozzle } \\
\text { sembly }\end{array}$ & $\begin{array}{l}\text { Throat velocity, } v_{i}(\mathrm{~m} \\
\left.\mathrm{s}^{-1}\right)\end{array}$ & $\begin{array}{l}\text { Throat mass flux range, } \\
G\left(\times 10^{4} \mathrm{~kg} \mathrm{~m}^{-2} \mathrm{~s}^{-1}\right)\end{array}$ & $\begin{array}{l}\text { Inlet temperature, } \\
T_{i n}\left({ }^{\circ} \mathrm{C}\right)\end{array}$ & $\begin{array}{l}\text { Cavitation } \\
\text { ber, } \sigma\end{array}$ \\
\hline 1 & $20,25,30,35,40,45,50$ & $2.4-5.4$ & 25 & $1.11-2.26$ \\
2 & $20,25,30,35,40,45,50$ & $2.4-6.05$ & 25 & $1.19-2.31$ \\
3 & $20,25,31,38$ & $2.4-4.6$ & 25 & $1.83-2.45$ \\
4 & $20,25,30,40,50$ & $2.4-6.0$ & 30 & $0.33-0.65$ \\
5 & $20,25,30,35,40,50$ & $2.4-6.0$ & 30 & $0.34-0.65$ \\
6 & $25,35,45,50$ & $3.0-6.0$ & 30 & $0.23-0.36$ \\
7 & $20,25,30,40,50$ & $2.4-6.0$ & 30 & $0.17-0.35$ \\
8 & $20,25,30,35,40,49$ & $2.4-5.8$ & 30 & $0.22-0.38$ \\
9 & $20,25,30,40,49$ & $2.4-5.8$ & 30 & $0.22-0.38$ \\
10 & $20,25,30,35,38$ & $2.4-4.5$ & 30 & $0.43-0.64$ \\
11 & $20,25,30,38$ & $2.4-4.5$ & 30 & $0.43-0.64$ \\
\hline
\end{tabular}

Table 2: Operating conditions for nozzle tests

is the characteristic temperature drop given by e.g.[15]. Properties in Table 3 and for all data analysis are from NIST REFPROP database [28, 29].

\begin{tabular}{|c|c|c|}
\hline$T_{i n}\left({ }^{\circ} \mathrm{C}\right)$ & 25 & 30 \\
\hline$\rho_{g}\left(\mathrm{~kg} \mathrm{~m}^{-3}\right)$ & 32.3 & 37.5 \\
$\rho_{f}\left(\mathrm{~kg} \mathrm{~m}^{-3}\right)$ & 1206.8 & 1187.5 \\
$i_{f g}\left(\mathrm{~kJ} \mathrm{~kg}^{-1}\right)$ & 177.8 & 173.1 \\
$C_{p, f}\left(\mathrm{~kJ} \mathrm{~kg}^{-1} \mathrm{~K}^{-1}\right)$ & 1.425 & 1.45 \\
$\Delta T^{*}(\mathrm{~K})$ & 3.34 & 3.78 \\
\hline
\end{tabular}

Table 3: Properties of R134a for the two saturation conditions considered in this paper (from [28, 29]

For all experiments, inlet temperature and saturation temperature at the nozzle exit (through the backpressure) were held constant and equal, and throat velocity was controlled using the pump variable-frequency drive. Each test case included heated and unheated runs. For the heated case, the nozzle heater voltage was manually adjusted using a variable autotransformer until the average wall temperature reached a set temperature. Measurements were taken as soon as the system reached steady state indicated by pressures and temperatures within $\pm 1 \mathrm{kPa}$ and $\pm 0.5^{\circ} \mathrm{C}$ inside the nozzle for at least 15 minutes. Data from all sensors were recorded at 5 second intervals throughout each test point. The data reported represented 15 minutes (180 pt) averages for all of the measurements.

\subsection{Data Reduction}

Five derived quantities were computed from the measured flow rate, temperatures and pressures: heat transfer coefficient, flow quality, Reynolds number, Mach number, and Nusselt number. The following sections describe how these parameters were computed along with a discussion about estimating the local fluid temperature. 


\subsubsection{Fluid Temperature}

For adiabatic data, fluid temperature can be assumed to be the local measured wall temperature. This would only be inconsistent in the case of large temperature gradients in the aluminum wall — which were minimized by insulating the exterior of the nozzle. For the heated data, while wall temperature will significantly exceed fluid temperature, fluid temperature could be estimated from the saturation temperature corresponding to the measured fluid pressure. However, due to finite growth of vapor bubbles, it is expected that the fluid is not at equilibrium, especially close to the throat. This is demonstrated by Figure 4a which gives the ratio of measured pressure to saturation pressure derived from wall temperature for all of the adiabatic data versus area ratio (ratio of local cross sectional area to that of the throat). The data indicate that, close to the throat, the measured pressure drops further (up to $20 \%$ ) than the equilibrium saturation temperature, and thus is not in equilibrium. Using the saturation temperature will thus underestimate the true heat transfer coefficients close to the throat. An alternative method for estimating fluid temperature for the heated case is to use the wall temperature profile from the adiabatic case. For this to be a good estimate of fluid temperature for the heated case, heating the wall must not significantly change the hydrodynamics of the flow. Figure $4 \mathrm{~b}$ show the differences between the pressure profiles of the heated and adiabatic cases. The differences are minor $(<5 \%)$, indicating that adding heat does not significantly change the flow profile. Thus, in the subsequent analysis, fluid temperature was estimated by the adiabatic wall temperature. This temperature was used both in formulating the heat transfer coefficient as well as evaluating local fluid properties.

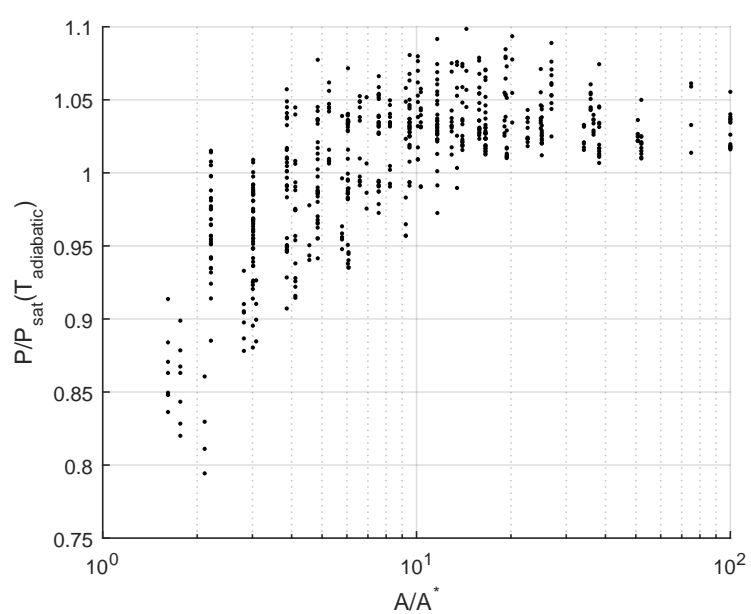

(a) $P / P_{\text {sat }}\left(T_{\text {adiabatic }}\right)$ vs. $A / A^{*}$ for all data.

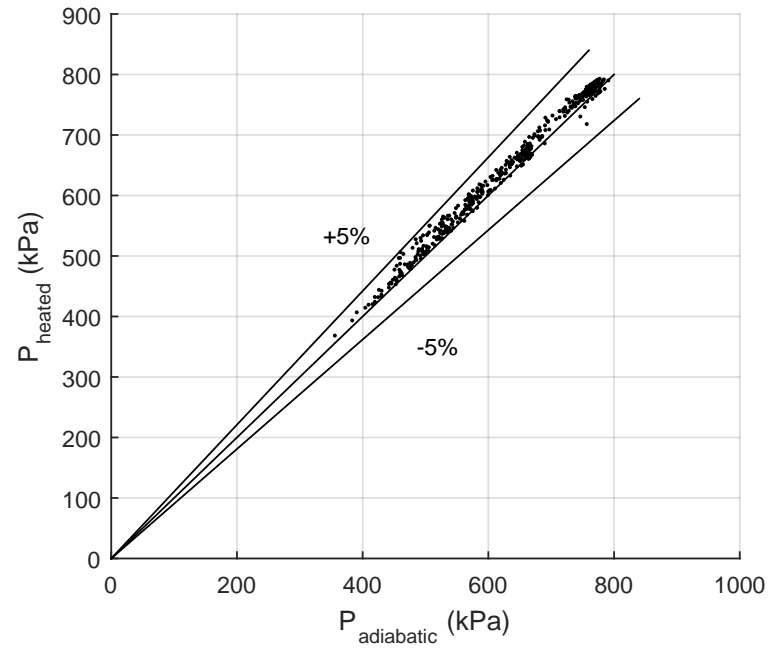

(b) Similarity of pressure profiles between heated and adiabatic case

Figure 4: Illustration of the non-equilibrium effects. 


\subsubsection{Heat transfer coefficient}

The following expression was used to evaluate the local average heat transfer coefficient:

$$
h=\frac{q^{\prime \prime}}{T_{w}-T_{f}},
$$

where $q^{\prime \prime}$ is the average heat flux on the wetted area of the puck, $T_{w}$ is the wall temperature of the puck, and $T_{f}$ is the local bulk temperature of the fluid. The local wall temperatures were measured directly with the nozzle puck thermocouples.

The heat flux was computed assuming that individual pucks were insulated from each other - that there was no axial conduction between pucks. Thus the local heat flux was given by the heat generated by the heater in each puck divided by the wetted surface area in that puck. Expressly,

$$
q^{\prime \prime}=\frac{2 V^{2} L_{p}}{R L_{H} A_{w}},
$$

where $V$ is the voltage across the heater, $R$ is the heater resistance, $L_{p}$ is the axial length of the puck, $L_{H}$ is the length of the heater, and $A_{w}$ is the wetted surface area of the inside of the puck.

While the thermal resistance between the pucks was certainly higher than that of a single block of aluminum because of imperfect surface finish with trapped air, additional analysis was required to validate this assumption. To do this, a conduction simulation was set up for three representative nozzle configurations1, 6, and 11 from Table 2-to determine the effect of less than infinite contact resistance on the derived heat flux.

ANSYS Fluent was used to solve the conduction problem in the entire nozzle assembly and evaluate the local heat fluxes numerically. Boundary conditions for four different surfaces on the nozzle assembly were required: 1) the inner wall surface downstream of the throat, 2) the heater cartridge contact area, 3) upstream and downstream boundaries, and 4) the wetted area upstream of the throat (Figure 5). The problem was set up as a 2D problem with radial symmetry around the central axis of the nozzle.

The inner wall surface downstream of the throat was set to the temperature measured by the experiments. Linear interpolation was used to infer a wall temperature between the thermocouple locations. The outer surface of the 2D section - at the radial location of the hole for the heater cartridge - was set to a constant uniform heat flux determined by the heater cartridge power and lateral surface area. The exposed surface of the beginning and end pucks were insulated. The inner wall surface upstream of the throat was set as a single phase convection boundary using the Dittus-Boelter correlation to obtain heat transfer coefficients varying with throat velocity from $16-36 \mathrm{~kW} \mathrm{~m}^{-2} \mathrm{~K}^{-1}$. The upstream fluid temperature was assumed to be constant and equal to the upstream set point value.

Four contact conductances between the pucks were simulated $-2200,12000,25000$, and $\infty \mathrm{W} \mathrm{m}^{-2} \mathrm{~K}^{-1}$. This is based on an expected range for aluminum to aluminum contact of between 2200 and 25000 (see for example [30]). For each nozzle configuration, the highest and lowest throat velocity cases were simulated. A 


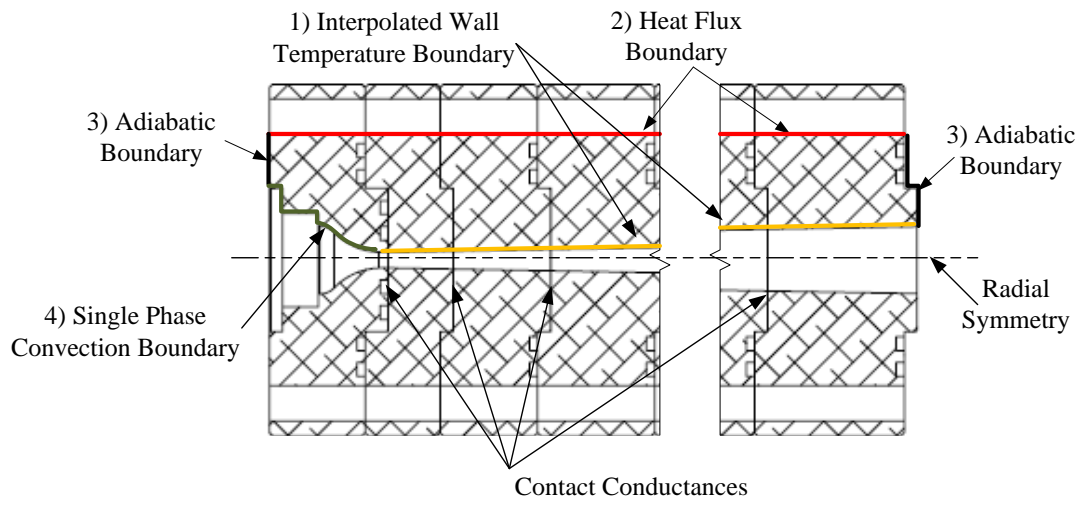

Figure 5: Boundary conditions for conduction simulation.

grid independence study was completed to ensure convergence of the heat flux measurement within $\pm 0.3 \%$. Following the simulation, the normal heat flux averaged over the wetted surface area of each was extracted from the simulation.

The results indicated that, for the perfect conduction case $\left(\mathrm{hc}=\infty \mathrm{W} \mathrm{m}^{-2} \mathrm{~K}^{-1}\right)$, there was significant variation in the agreement with the direct calculation from equations (2) and (3). At the high heat fluxes, this variation primarily was within $\pm 20 \%$, however at low heat flux, the relative error was much more significant. On the other hand, for all of the simulation cases with a finite contact resistance, the simulation results agreed with the direct heat flux calculation within $\pm 1 \%$ for all pucks downstream from the nozzle. Based on this data, it was concluded that adding an additional $\pm 1 \%$ to the uncertainty of the heat flux measurement appropriately accounted for the uncertainty due to axial conduction.

\subsubsection{Flow Quality}

The flow quality downstream from the throat was found using an energy balance on a control volume around the interior of the nozzle from upstream of the throat to the nozzle section of interest. It was assumed that the fluid downstream from the throat was saturated and properties could be evaluated directly from the local fluid temperature. The enthalpy upstream from the throat was evaluated from the measured inlet temperature and pressure. Solving the energy equation for quality yields

$$
x=\frac{\frac{\dot{Q}_{C V}}{\dot{m}}+\left(\frac{v_{i}^{2}}{2}-\frac{v_{e}^{2}}{2}\right)+i_{f}\left(T_{i}, P_{i}\right)-i_{f}\left(T_{e}\right)}{i_{f g}\left(T_{e}\right)},
$$

where $\dot{Q}_{C V}$ is the total heat added through all sections from the throat to (and including) the section of interest, $\dot{m}$ is the mass flow rate through the nozzle, $v_{i}$ is the velocity upstream of the throat, $v_{e}$ is the velocity at the section of interest, $i_{f}\left(T_{i}, P_{i}\right)$ and $i_{f}\left(T_{e}\right)$ are the enthalpies of the fluid at the inlet of the 
nozzle and exit of the puck respectively, and $i_{f g}\left(T_{e}\right)$ is the latent heat of vaporization at the exit of the puck. Assuming no slip between the phases, the exit velocity is given by

$$
v_{e}=G\left(\frac{x}{\rho_{g}}+\frac{1-x}{\rho_{f}}\right),
$$

where $G$ is the mass flux through the nozzle computed using the average cross-sectional area of the puck. Substituting (5) into (4) yields a quadratic equation in $x$,

$$
a_{2} x^{2}+a_{1} x+a_{0}=0
$$

where

$$
\begin{aligned}
& a_{2}=\frac{1}{2} G^{2}\left(\frac{1}{\rho_{g}^{2}}-\frac{2}{\rho_{g} \rho_{f}}+\frac{1}{\rho_{f}^{2}}\right) \\
& a_{1}=G^{2}\left(\frac{1}{\rho_{g}}-\frac{1}{\rho_{f}^{2}}\right)+i_{f g}\left(T_{e}\right) \\
& a_{0}=\frac{1}{2}\left(\frac{G^{2}}{\rho_{f}^{2}}-v_{i}^{2}\right)-i_{f}\left(T_{i}\right)+i_{f}\left(T_{e}\right)-\frac{\dot{Q}_{C V}}{\dot{m}} .
\end{aligned}
$$

This equation has two real roots and can easily be solved either numerically or analytically with the nonnegative root giving the correct solution.

\subsubsection{Reynolds Number}

Various definitions for Reynolds number exist for two phase flow. We adopted the superficial liquid Reynolds number following the definition for Chen's correlation [31] given by

$$
\operatorname{Re}=\frac{G(1-x) D}{\mu_{f}}
$$

where $D$ is the average diameter and $\mu_{f}$ is the dynamic viscosity of the liquid evaluated at the adiabatic wall temperature.

\subsubsection{Cavitation Number}

Cavitation number is defined as

$$
\sigma=\frac{P_{i}-P_{s a t}\left(T_{i}\right)}{1 / 2 \rho v_{i}^{2}}
$$

where $v_{i}$ was the upstream flow velocity computed from the mass flow rate and cross-sectional area common to all inlet profiles $(D=10.42 \mathrm{~mm})$.

\subsubsection{Mach Number}

Various models exist to estimate the speed of sound of the two phase mixture, but any one model requires an assumption about the equilibrium nature of the flow as well as the flow regime. Four of the more simple 
models from the literature are the homogeneous frozen model (HFM), the homogeneous equilibrium model (HEM), the annular flow model with no slip (AFM), and the slug flow model (SFM). HFM assumes the phases are dispersed uniformly throughout the flow and that no mass transfer occurs between the phases. The following classic expression gives the speed of sound using this model (see [32-34]):

$$
c_{h}=\left\{\rho_{h}^{2}\left(\frac{x}{\rho_{g}^{2} c_{g}^{2}}+\frac{1-x}{\rho_{f}^{2} c_{f}^{2}}\right)\right\}^{-1 / 2},
$$

with $\rho_{h}$ given by

$$
\rho_{h}=\left(\frac{1-x}{\rho_{f}}+\frac{x}{\rho_{g}}\right)^{-1} .
$$

If mass transfer between the phases is considered, this extends to the HEM:

$$
c_{h}=\left\{\rho_{h}^{2}\left(\frac{x}{\rho_{g}^{2} c_{g}^{2}}+\frac{1-x}{\rho_{f} c_{f}^{2}}\right)-\left.\left(\frac{1}{\rho_{g}}-\frac{1}{\rho_{f}}\right) \frac{d x}{d p}\right|_{s}\right\}^{-1 / 2} .
$$

For annular flow assuming a unity slip ratio, Nguyen et al. [32] propose the following expression for speed of sound:

$$
c_{h}=\left\{\left(\frac{\alpha}{\rho_{g} c_{g}^{2}}+\frac{1-\alpha}{\rho_{f} c_{f}^{2}}\right)^{-1}\left(\frac{\alpha}{\rho_{g}}+\frac{1-\alpha}{\rho_{f}}\right)\right\}^{1 / 2},
$$

where $\alpha$ is the void fraction and is defined as (for unity slip ratio)

$$
\alpha=\frac{x \rho_{f}}{\rho_{f} x+(1-x) \rho_{g}} .
$$

Lastly, the SFM is proposed by Henry, Grolmes and Fauske [35] as the following:

$$
c_{h}=\frac{c_{f} c_{g}}{\alpha c_{f}+(1-\alpha) c_{g}},
$$

with $\alpha$ defined the same way as in the separated model. These models yield significantly different results. Figure 6 shows a plot of speed of sound for the four different models versus void fraction for R-134a at $770 \mathrm{kPa}$ saturation pressure. HEM yields the lowest speed of sound with speeds at low qualities almost ten times smaller than for high qualities. There is also a discontinuity between the speed at sub-cooled liquid and saturated liquid with a small, non-zero quality. SFM yields the highest speed of sound at low qualities, because for locations containing only a liquid slug, the sound moves at the much higher speed of sound in liquid. The other models yield results in-between these limits.

Regardless of the speed of sound model, the two phase Mach number is given by

$$
\mathrm{M}=\frac{G}{c}\left(\frac{x}{\rho_{g}}+\frac{1-x}{\rho_{f}}\right),
$$

where $c$ is given by any one of the models (12)-(17). All properties for the evaluation of Mach number were evaluated at the local adiabatic wall temperature. 


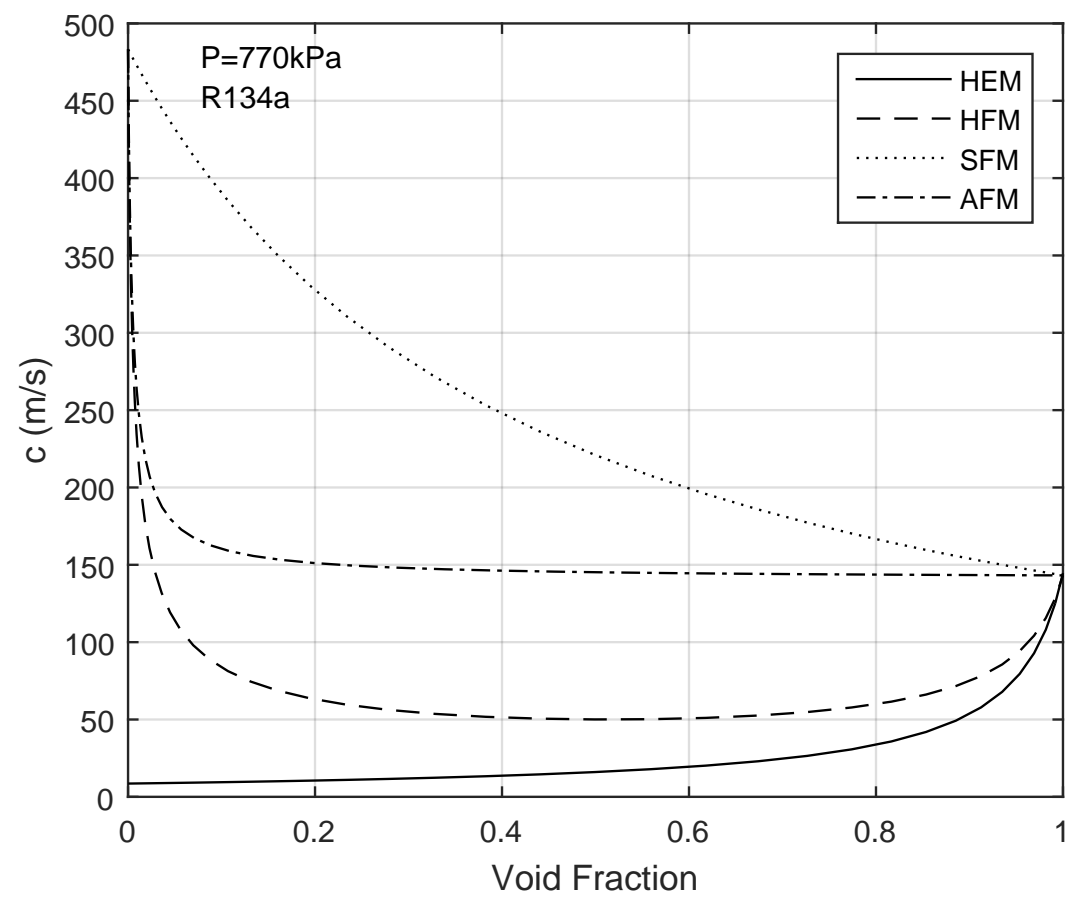

Figure 6: Plot of speed of sound for four different models versus void fraction.

\subsubsection{Nusselt Number}

While often for two-phase flow, heat transfer coefficients are given in dimensional form to avoid the ambiguity of non-dimensionalizing by liquid or vapor properties, because the primary dimension, diameter, is changing along the length of the nozzle, using Nusselt number is useful to remove the area-effect from the data. Thus, the Nusselt number was computed from data using the following definition:

$$
\mathrm{Nu}=\frac{h D}{k_{f}},
$$

where $h$ is the local average heat transfer coefficient, $D$ is the average diameter of the puck and $k_{f}$ is the thermal conductivity of the saturated liquid evaluated using the local adiabatic wall temperature.

\subsection{Uncertainty Analysis}

The uncertainty in the measured heat transfer coefficient and quality was estimated using the propagation of error method assuming that the measurement errors were not correlated. For heat transfer coefficient, three components contribute to uncertainty: uncertainty in the wall temperature, fluid temperature, and heat flux. For quality, four components contribute to the uncertainty: fluid temperature, inlet temperature, mass flow rate, and heat flux (for the heated case). The sensitivity coefficients were computed from the expressions in Table 3 evaluated at each data point. The uncertainty estimates for temperature represent 
the maximum bias uncertainty over the calibration range given the accuracy and stability of the calibration bath. The uncertainty of the heat flux measurement includes the uncertainty of the heater resistance and the DAQ voltage measurement used to measure the heater power along with uncertainty due to axial conduction from the conduction simulation study. Also included is a $\pm 1 \%$ uncertainty estimating the heat loss due to finite insulation. The uncertainty of the mass flow was from manufacturer specifications of the meter. Error bars reflecting the uncertainty analysis are present on all of the heat transfer plots. Ninety four percent of the data had heat transfer uncertainty less than $\pm 20 \%$. Quality plots also show error bars, though for some cases, bars are smaller than the marker size. Ninety percent of the quality measurements greater than 0.02 had quality uncertainty less than $\pm 5 \%$.

\begin{tabular}{ll|ll}
\hline \hline Sensitivity & Expression & Uncertainty & Value \\
\hline$\frac{\partial q^{\prime \prime}}{\partial V}$ & $\frac{4 V L_{p}}{R L_{H} A_{w}}$ & $\pm(3.5 \mathrm{e}-4 \mathrm{~V}+3.5 \mathrm{e}-4300 \mathrm{~V})$ \\
$\frac{\partial q^{\prime \prime}}{\partial R}$ & $-\frac{2 V^{2} L_{p}}{R^{2} L_{H} A_{w}}$ & $U_{V}$ & $\pm(3.5 \mathrm{e}-4 \mathrm{R}+3.5 \mathrm{e}-4100 \Omega)$ \\
$\delta q^{\prime \prime}$ & - & $U_{R}$ & $2 \%$ of value \\
\hline$\frac{\partial h}{\partial T_{w}}$ & $\frac{-q^{\prime \prime}}{\left(T_{w}-T_{f}\right)^{2}}$ & - & $\pm 0.15^{\circ} \mathrm{C}$ \\
$\frac{\partial h}{\partial T_{f}}$ & $\frac{q^{\prime \prime}}{\left(T_{w}-T_{f}\right)^{2}}$ & $U_{T_{w}}$ & $\pm 0.15^{\circ} \mathrm{C}$ \\
$\frac{\partial h}{\partial q^{\prime \prime}}$ & $\frac{1}{T_{w}-T_{f}}$ & $U_{T_{f}}$ & From above \\
\hline$\frac{\partial x}{\partial T_{f}}$ & $-\frac{\frac{\partial a_{0}}{\partial T_{f}}+\frac{\partial a_{1}}{\partial T_{f}} x+\frac{\partial a_{2}}{\partial T_{f}} x^{2}}{\partial a_{2} x+a_{1}}$ & $U_{T_{f}}$ & $\pm 0.15^{\circ} \mathrm{C}$ \\
$\frac{\partial x}{\partial T_{i}}$ & $-\frac{\frac{\partial a_{0}}{\partial T_{i}}}{2 a_{2} x+a_{1}}$ & $U_{T_{i}}$ & $\pm 0.15^{\circ} \mathrm{C}$ \\
$\frac{\partial x}{\partial P_{i}}$ & $-\frac{\partial a_{0}}{\partial P_{i}}$ & $\pm 2 a_{i}$ & $\pm 1.75 \mathrm{kPa}$ \\
$\frac{\partial x}{\partial \dot{m}}$ & $-\frac{\partial a 0}{\partial \dot{m}+\frac{\partial a_{1}}{\dot{m}} x+\frac{\partial a_{2}}{\dot{m}} x^{2}}$ & $U_{P_{i}}$ & \pm 0.1 of reading \\
$\frac{\partial x}{\partial q^{\prime \prime}}$ & $\frac{\partial a_{0}}{\partial q^{\prime \prime}}$ & $U_{\dot{m}}$ & From above \\
\hline
\end{tabular}

Table 4: Expressions for sensitivity coefficients.

\section{Results and Discussion}

\subsection{Temperature Drop}

Figure 7 shows the B-factor profile and quality versus area ratio for high and low velocity runs of the adiabatic case, where B-factor is given by:

$$
B=\frac{T_{i n}-T}{\Delta T^{*}}
$$

and $\Delta T_{*}$ is the characteristic temperature drop from (1). Figure 7 a shows a throat velocity of $50 \mathrm{~m} \mathrm{~s}^{-1}$. Square inlets for this velocity are not shown since the maximum velocity obtained by these inlets was only $38 \mathrm{~m} \mathrm{~s}^{-1}$ (due to pump limitation). Multiple runs with the same inlet geometry but different length show close similarity. B-factors from all of the inlets except A, reach the same maximum value of 4 . This is equivalent to approximately $16.3^{\circ} \mathrm{C}$. Figure $7 \mathrm{~b}$ shows a throat velocity of $25 \mathrm{~m} \mathrm{~s}^{-1}$, including data for the 
square inlet cases. At this velocity, there is still remarkable consistency between nozzles with the same inlet geometry, but there are greater temperature drop variations between different inlets. The large diameter square inlet (B2) generates the most vapor and yields the largest temperature drop
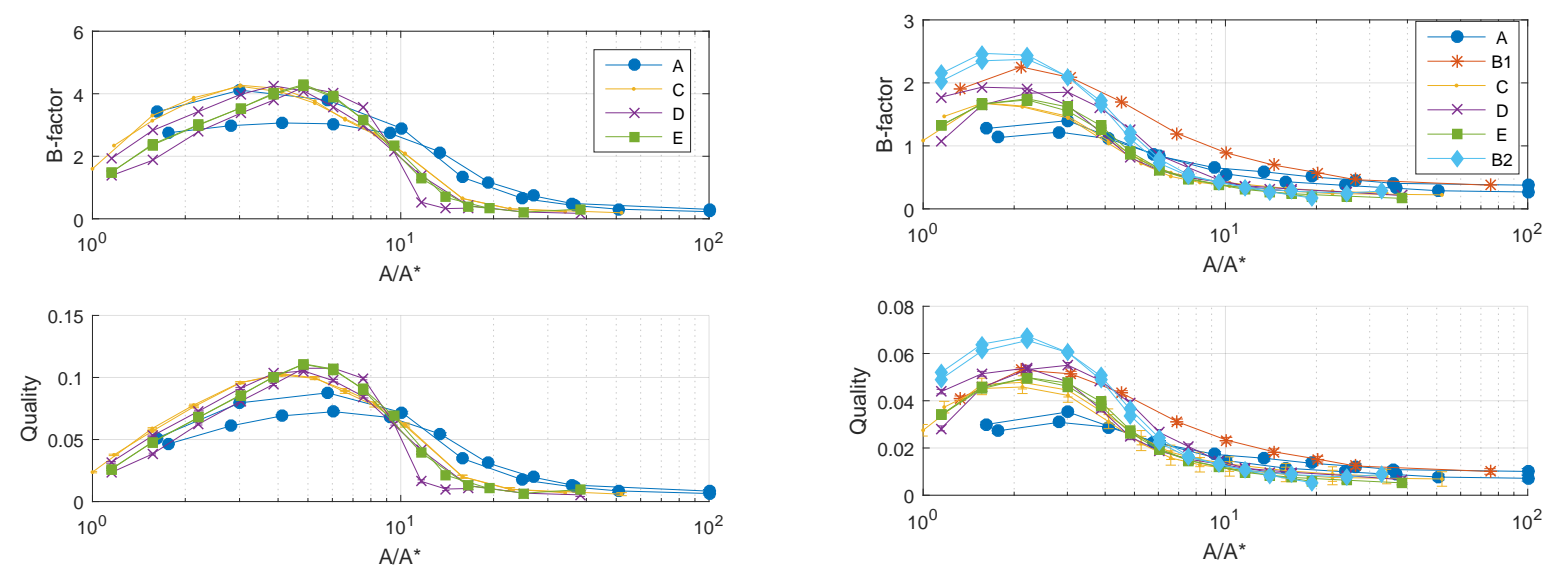

(a) $50 \mathrm{~m} \mathrm{~s}^{-1}$ for all non-square inlets

(b) $25 \mathrm{~m} \mathrm{~s}^{-1}$ for all inlets

Figure 7: Dimensionless temperature versus area ratio and quality versus area ratio.

Figure 8 plots the maximum B-factor versus throat Reynolds number for all of the data runs. There is a strong correlation between throat Reynolds number and maximum B-factor with higher Reynolds number giving greater temperature drop. The trend begins to fail at higher Reynolds numbers-indicating that increase of throat velocity will not continue to drop the temperature.

\subsection{Heat Transfer}

Figure 9 is a plot of the measured heat transfer coefficient in terms of liquid Nusselt number versus superficial liquid Reynolds number for the various geometry and flow cases. The data seem to collapse for all of the runs in the low Reynolds number region (far from throat), whereas they spread out at high Reynolds numbers (close to throat), separating into two regimes. Interestingly, while all of the $\mathrm{E}$ data fell into the upper regime, the square inlets (B1 \& B2) and D show data in both, with nozzle length the only geometry difference between the data.

For comparison, Chen's correlation for flow boiling [31] was plotted on top of this data. This correlation contains two summed parts, a convective evaporation term based on the Dittus-Boelter correlation and a nucleate boiling term based on Forster and Zuber [36]. The nucleate boiling term of Forster and Zuber is based on the proposition that the heat transfer due to bubble growth can be correlated with a Reynolds number based on a growing bubble radius from the thermally-controlled asymptotic Rayleigh-Plesset equation. An enhancement factor in the convection term describes the enhancement due to increased flow acceleration by 


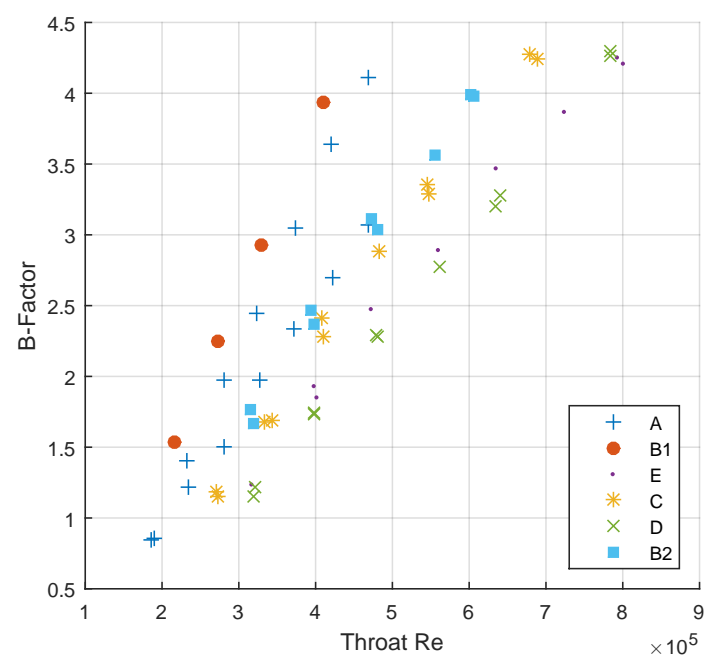

Figure 8: Plot showing maximum B-factor versus throat Reynolds number.

vapor generation. A similar suppression term reduces the effect of nucleate boiling since the superheat is reduced due to fluid motion. The $\mathrm{F}$ and $\mathrm{S}$ terms were computed from the correlations proposed by Bennett and Chen [37].

For all results computed by Chen's correlation, the convective term dominated except for the low Reynolds number region at the end of the nozzles (where the maximum nucleate boiling to convective ratio was 0.86 ). The low Reynolds number region shows good correlation with Chen's results, whereas at high Reynolds numbers, the data either fall significantly above or below the correlation. The data falling above the correlation can be explained by nucleate boiling enhanced beyond that predicted by the Forster and Zuber term since the bubble growth is driven not only by wall superheat, but also by pressure drop. Analysis by Jones and Zuber show that under linear decompression, bubble growth rates far exceed those indicated by the asymptotic solution under constant superheat $\left(R(t) \sim t^{3 / 2}\right.$ instead of $R(t) \sim t^{1 / 2}$ for the asymptotic solution).

The data falling under the correlation are likely explained by flow-detachment immediately after the throat - a phenomena which has been previously seen in flow visualizations [17, 20].

Another significant conclusion from the comparison with Chen's correlation is that some of the heat transfer coefficients are significantly higher than other comparable single phase or two-phase heat transfer coefficients. Figure 9 indicates that a number of points are as high as $\mathrm{Nu}=10,000$, corresponding to $\mathrm{h}=$ $285 \mathrm{~kW} \mathrm{~m}^{-2} \mathrm{~K}^{-1}$. This is higher than $100 \mathrm{~kW} \mathrm{~m}^{-2} \mathrm{~K}^{-1}$ cited by [22] as the highest recorded heat transfer coefficient for R-134a. Thus these nozzles have a significant potential for application to high heat density cooling.

Due to the dominance of convective evaporation and decompression-driven phase change along with the 


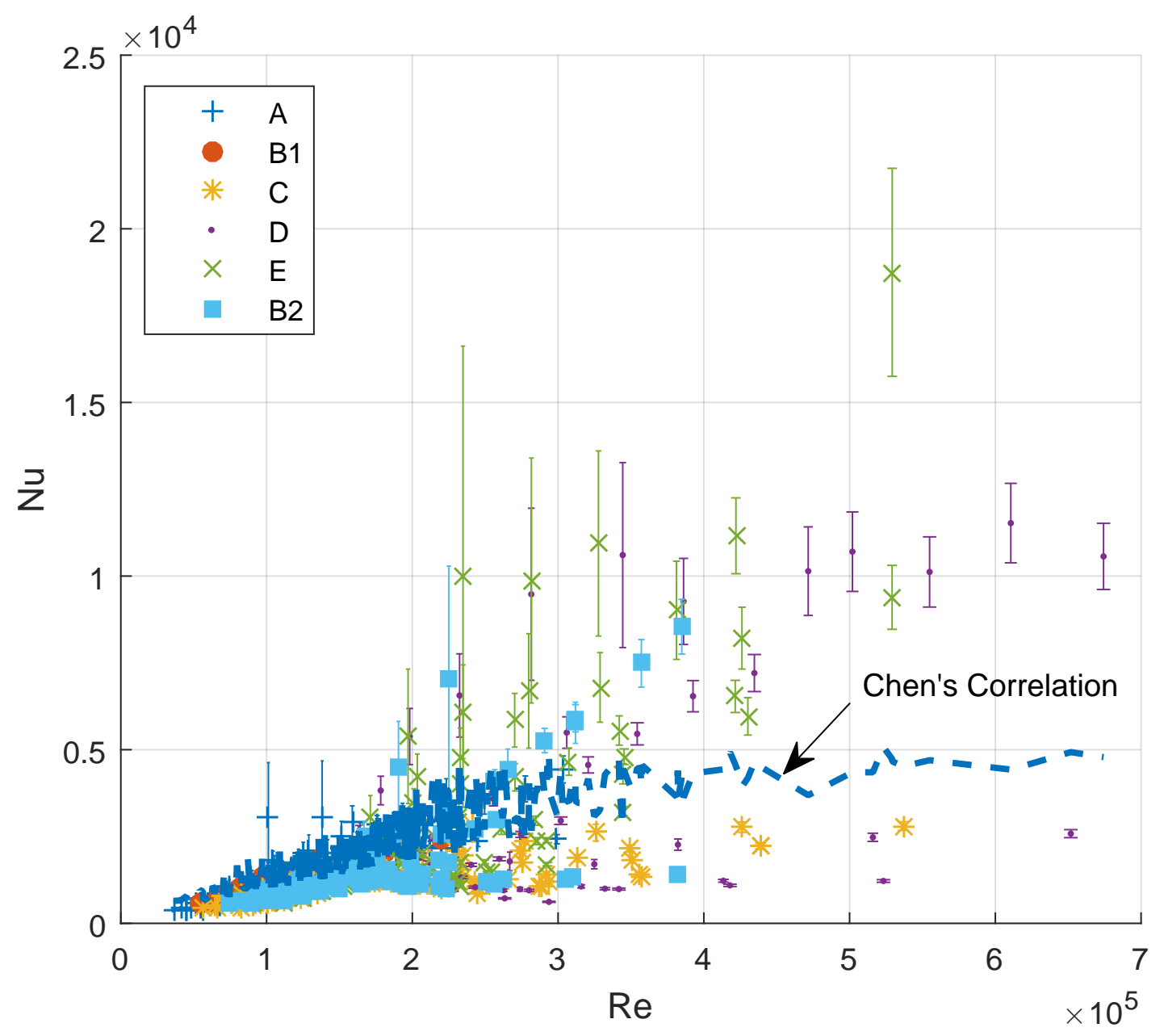

Figure 9: Comparison of heat transfer results with Chen's correlation. 
fact that local heat flux was correlated to Reynolds number due to area increase along the nozzle, the heat transfer showed no clear correlation with heat flux, thus the heat flux is not plotted with the heat transfer coefficient.

Figure 10 shows how different geometry parameters affect the maximum (over all pucks at a given throat velocity) Nusselt number. Figure 10a shows maximum Nusselt number versus throat diameter showing that the larger throat diameter nozzles reach a higher maximum Nusselt number. Figure 10b compares max Nusselt number versus divergence angle for nozzle configurations 1-3. Only configurations 1-3 were presented, since for these configurations, both $1^{\circ}$ and $1.5^{\circ}$ angles were used for the same inlet geometry. The data suggest that the more gradual diverging angle yielded higher heat transfer coefficients.

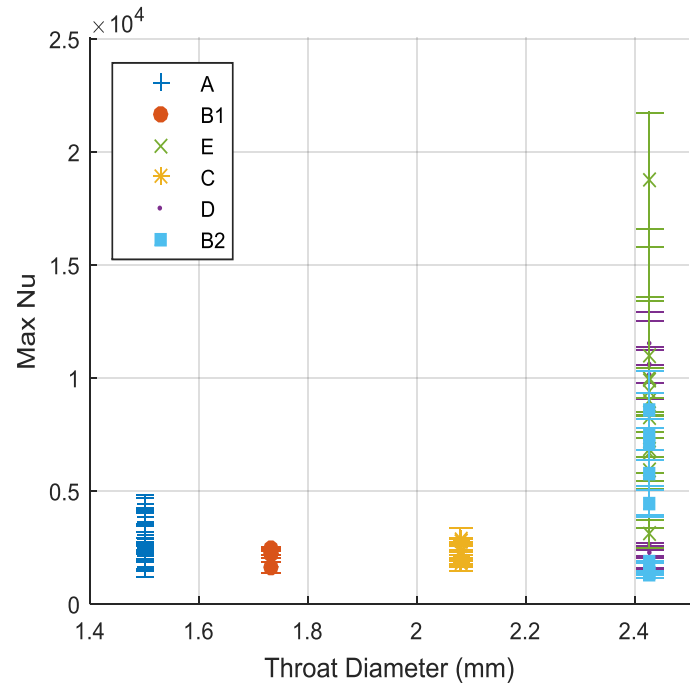

(a) $\mathrm{Nu}$ vs. throat diameter

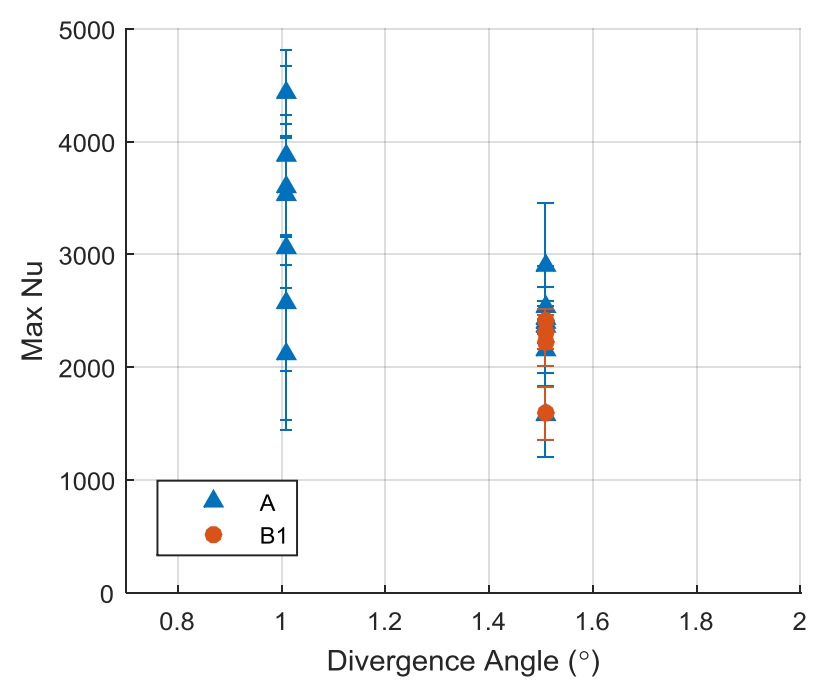

(b) $\mathrm{Nu}$ vs. divergence angle

Figure 10: Comparison between heat transfer coefficient and nozzle geometry.

\subsection{Compressibility}

Since these nozzles contain two-phase fluid at high mass-flux, compressibility likely plays a significant role in the flow characteristics. Supersonic flow in the diverging section would result in potential acceleration and longer pressure decrease leading to larger temperature depression and increased heat transfer coefficients over a longer section of the nozzle. As mentioned earlier, two phase speed of sound is strongly dependent on flow regime, and many different models have been proposed for computing this quantity. Figure 11 compares the pressure profile for nozzle configuration 6 with D at $50 \mathrm{~m} \mathrm{~s}^{-1}$ with different speed of sound models given in terms of Mach number. As is shown, two of the models (HEM and HFM) indicate that the flow, post throat is supersonic $(M>1)$. This matches with the fact that the pressure profile has a negative 
slope initially, despite the nozzle diverging. For the HFM, the transition through $M=1$ occurs approximately at the minimum pressure point. Despite these factors, several reasons prevent this from being conclusive:

1. Both separated flow sonic models show that $M<1$ everywhere, and thus sub-sonic. While it is unlikely, at least initially, that the flow is separated, one can imagine various possibilities where the flow indeed separates.

2. Friction would allow a $s u b$-sonic flow to have an extremum in pressure somewhere in the diverging section.

3. During data collection, the back-pressure was held constant at a saturation temperature equal to the inlet temperature; thus, it could not be determined whether or not a choked condition occurred from the flow rate.

Because of these things, it is uncertain if compressibility plays a dominant role in the pressure profiles and thus heat transfer. Additional experimentation including flow visualization or high speed pressure data is necessary to come to a firm conclusion on this. However, since this question primarily only affects how one could modify the flow conditions to give a more advantageous driving pressure profile, this ambiguity does not invalidate the results for the presented data.

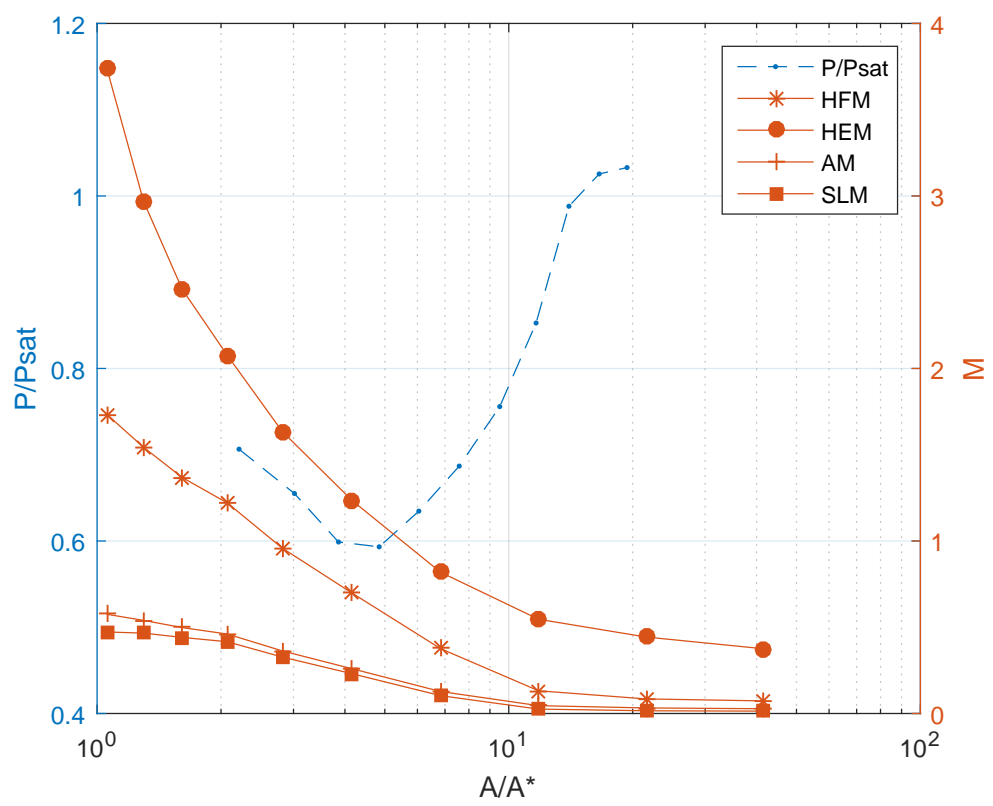

Figure 11: Comparison between speed of sound models for inlet $\mathrm{C}, 50 \mathrm{~m} \mathrm{~s}^{-1}$. 


\section{Conclusions}

Heat transfer and flow parameters of cavitating flows in the diverging section of a converging-diverging nozzle were investigated experimentally. Temperature profiles, temperature drop, and heat transfer coefficients were measured for eleven different nozzles. The following conclusions can be drawn:

1. A temperature drop of as much as $16.3^{\circ} \mathrm{C}$ was observed due to the bubble formation caused by the pressure drop.

2. Temperature drop showed a strong correlation with throat Reynolds number and a weak correlation with inlet geometry.

3. Very high heat transfer coefficients were obtained - up to $285 \mathrm{~kW} \mathrm{~m}^{-2} \mathrm{~K}^{-1}$.

4. Two different heat transfer regimes are suggested - a high and low heat transfer regime. It is postulated that these two regimes have to do with whether the wall remains wetted immediately post throat.

5. The high heat transfer regime was likely due to rapid bubble growth at the wall due to local pressure decompression.

6. It was impossible to determine whether or not the flow was sonic due to the diversity of speed of sound models for two-phase flow and the ambiguity of the momentum equation. The Mach number showed no significant correlation with the heat transfer coefficient beyond what was found with Reynolds number.

Further work would investigate the cause of wall separation for the low heat transfer regime in order to determine a nozzle/flow condition design that prevents this. Flow visualization work or high speed pressure transducer measurements would allow a proper determination of sonic effects. Additionally, application of cavitation-enhanced heat transfer to electronics cooling would require an analysis of the noise level and vibrations induced by bubble growth and collapse.

\section{Acknowledgments}

The authors would like to thank Matt Kluitenberg, Andrew Featherstone, and Eric Johnson for performing the data collection for this project.

\section{References}

[1] M. M. Vieira, J. Simoes-Moreira, Low-pressure flashing mechanisms in iso-octane liquid jets, Journal of Fluid Mechanics 572 (2007) 121-144.

[2] R. D. Oza, J. F. Sinnamon, An experimental and analytical study of flash-boiling fuel injection, Report, SAE Technical Paper (1983).

[3] J. R. Simoes-Moreira, J. E. Shepherd, Evaporation waves in superheated dodecane, Journal of Fluid Mechanics 382 (1999) $63-86$. 
[4] T. Shin, O. Jones, Nucleation and flashing in nozzles-1. A distributed nucleation model, International journal of multiphase flow 19 (6) (1993) 943-964.

[5] E. Starkman, V. Schrock, K. Neusen, D. Maneely, Expansion of a very low quality two-phase fluid through a convergentdivergent nozzle, Journal of Fluids Engineering 86 (2) (1964) 247-254.

[6] N. Sandhu, G. Jameson, An experimental study of choked foam flows in a convergent-divergent'nozzle, International Journal of Multiphase Flow 5 (1) (1979) 39-58.

[7] R. F. Tangren, C. H. Dodge, H. S. Seifert, Compressibility effects in twophase flow, Journal of Applied Physics 20 (7) (1949) 637-645. doi:doi:http://dx.doi.org/10.1063/1.1698449.

[8] R. E. Henry, H. K. Fauske, The two-phase critical flow of one-component mixtures in nozzles, orifices, and short tubes, Journal of Heat Transfer 93 (2) (1971) 179-187.

[9] Y. Hsu, Review of critical flow rate, propagation of pressure pulse, and sonic velocity in two-phase media, Report TN D-6814, National Aeronautics and Space Administration (1972).

[10] J. A. Vogrin Jr, An experimental investigation of two-phase, two-component flow in a horizontal, converging-diverging nozzle, Report, Argonne National Lab., Ill.; Associated Midwest Universities, Lemont, Ill. (1963).

[11] E. Goncalves, Modeling for non isothermal cavitation using 4-equation models, International Journal of Heat and Mass Transfer 76 (2014) 247-262.

[12] A. Preston, T. Colonius, C. E. Brennen, A numerical investigation of unsteady bubbly cavitating nozzle flows, Physics of Fluids (1994-present) 14 (1) (2002) 300-311.

[13] L. Noordzij, L. Van Wijngaarden, Relaxation effects, caused by relative motion, on shock waves in gas-bubble/liquid mixtures, Journal of Fluid Mechanics 66 (01) (1974) 115-143.

[14] R. Ishii, Y. Umeda, S. Murata, N. Shishido, Bubbly flows through a convergingdiverging nozzle, Physics of Fluids A: Fluid Dynamics (1989-1993) 5 (7) (1993) 1630-1643.

[15] M. G. De Giorgi, D. Bello, A. Ficarella, Analysis of thermal effects in a cavitating orifice using rayleigh equation and experiments, Journal of Engineering for Gas Turbines and Power 132 (9) (2010) 092901.

[16] C. F. Delale, e. Pasinliolu, Z. Bakaya, G. H. Schnerr, Semianalytical solution of unsteady quasi-one-dimensional cavitating nozzle flows, Journal of Engineering Mathematics 86 (1) (2014) 49-70.

[17] N. Tani, T. Nagashima, Cryogenic cavitating flow in 2D laval nozzle, Journal of Thermal Science 12 (2) (2003) $157-161$.

[18] J.-P. Franc, C. Rebattet, A. Coulon, An experimental investigation of thermal effects in a cavitating inducer, Journal of Fluids Engineering 126 (5) (2004) 716-723.

[19] J.-C. Park, M.-S. Han, S.-J. Kim, Investigation on the cavitation damage behavior with temperature and cavitation time in seawater, Surface and Interface Analysis 44 (11-12) (2012) 1407-1410.

[20] B. Schneider, A. Koşar, C.-J. Kuo, C. Mishra, G. S. Cole, R. P. Scaringe, Y. Peles, Cavitation enhanced heat transfer in microchannels, Journal of Heat Transfer 128 (12) (2006) 1293-1301. doi:10.1115/1.2349505.

[21] G. S. Cole, R. P. Scaringe, R. P. Roth, Y. Peles, System evaluation of cavitation enhanced heat transfer in microchannels, Report, SAE Technical Paper (2006).

[22] J. D. Sole, B. J. Shelofsky, R. P. Scaringe, G. S. Cole, Cavitation-enhanced microchannel heat exchanger demonstration and heat transfer correlation development using R-134a, in: ASME 2012 Heat Transfer Summer Conference collocated with the ASME 2012 Fluids Engineering Division Summer Meeting and the ASME 2012 10th International Conference on Nanochannels, Microchannels, and Minichannels, American Society of Mechanical Engineers, 2012, pp. 607-615.

[23] J. Yuan, M. Zeng, C. Guo, H. Cao, D. Tang, Experimental investigation of flow-boiling characteristics in a single microchannel with inlet cavitation structure, Proceedings of the Institution of Mechanical Engineers, Part N: Journal of Nanoengineering and Nanosystems (2014) 1740349914548293.

[24] P. Romstedt, W. Werner, Numerical analysis of critical two-phase flow in a convergent-divergent nozzle, Nuclear science 
and engineering 92 (1) (1986) 71-83.

[25] F. T. Kanizawa, T. S. Mogaji, G. Ribatski, Evaluation of the heat transfer enhancement and pressure drop penalty during flow boiling inside tubes containing twisted tape insert, Applied Thermal Engineering 70 (1) (2014) 328-340. doi:10.1016/j.applthermaleng.2014.05.029.

[26] F. J. do Nascimento, H. L. S. L. Leão, G. Ribatski, An experimental study on flow boiling heat transfer of R134a in a microchannel-based heat sink, Experimental Thermal and Fluid Science 45 (2013) 117-127. doi:10.1016/j.expthermflusci.2012.10.014.

[27] A. Kaya, M. R. Özdemir, A. Koşar, High mass flux flow boiling and critical heat flux in microscale, International Journal of Thermal Sciences 65 (0) (2013) 70-78. doi:http://dx.doi.org/10.1016/j.ijthermalsci.2012.10.021.

[28] E. W. Lemmon, M. L. Huber, M. O. McLinden, Nist standard reference database 23: Reference fluid thermodynamic and transport properties-refprop (2013).

[29] R. Tillner-Roth, H. D. Baehr, An international standard formulation for the thermodynamic properties of 1, 1, 1, 2tetrafluoroethane (hfc134a) for temperatures from $170 \mathrm{k}$ to $455 \mathrm{k}$ and pressures up to $70 \mathrm{mpa}$, Journal of Physical and Chemical Reference Data 23 (5) (1994) 657-729.

[30] Y. A. Çengel, J. Hernn Prez, Heat Transfer: A Practical Aapproach, 2nd Edition, McGraw-Hill, New York, NY, 2004.

[31] J. C. Chen, Correlation for boiling heat transfer to saturated fluids in convective flow, Industrial \& Engineering Chemistry Process Design and Development 5 (3) (1966) 322-329.

[32] D. L. Nguyen, E. R. F. Winter, M. Greiner, Sonic velocity in two-phase systems, International Journal of Multiphase Flow 7 (3) (1981) 311-320. doi:http://dx.doi.org/10.1016/0301-9322(81)90024-0.

[33] C. E. Brennen, Cavitation and bubble dynamics, Cambridge University Press, 2013.

[34] S. M. Ghiaasiaan, Two-phase flow, boiling, and condensation: in conventional and miniature systems, Cambridge University Press, 2007.

[35] R. Henry, M. Grolmes, H. Fauske, Propagation velocity of pressure waves in gas-liquid mixtures, Cocurrent Gas-Liquid Flow (Rhodes, E., Scott, DS, eds.) (1969) 1-18.

[36] H. Forster, N. Zuber, Dynamics of vapor bubbles and boiling heat transfer, AIChE Journal 1 (4) (1955) 531-535.

[37] D. L. Bennett, J. C. Chen, Forced convective boiling in vertical tubes for saturated pure components and binary mixtures, AIChE Journal 26 (3) (1980) 454-461. 